\title{
LA PROPIEDAD INTELECTUAL EN LA ESPAÑA CONTEMPORÁNEA, 1847-1936.
}

por

\section{RAQUEL SÁNCHEZ GARCÍA}

Universidad Complutense de Madrid

RESUMEN: El surgimiento del derecho de autor supuso el reconocimiento jurídico y social del trabajo intelectual en el siglo XVIII. Además, el estudio del derecho de autor y de la propiedad intelectual son elementos fundamentales para analizar la situación económica del autor. Por otra parte, estos elementos constituyen también parte importante para la bistoria de la edición porque mediante ellos podemos estudiar la figura del editor como empresario ya que la propiedad intelectual se convirtió en una forma de propiedad comercial. Este artículo pretende analizar el proceso en nuestro país, estudiando las diferentes cuestiones como la legislación, las actitudes de autores y editores y el desarrollo de asociaciones profesionales para la defensa de sus derechos.

Palabras clave: Historia de la edición. Propiedad intelectual. Autoría-Legislación.

ABSTRACT: The emergence of authorial rights meant legal and social recognition for intellectual work in the eighteenth century. Therefore, the study of the rights of authorship and intellectual property is important in understanding the economic situation of authors and editors. At the same time, these elements are also important for the history of publishing because we can study editors as businessmen once intellectual property became a type of commercial property. This article aims to analyse this process in Spain, addressing different questions such as legislation, the attitude of authors and editors, and the development of professional associations for the defence of their rights.

KEY WORDS: Publishing history. Intellectual property. Authorship.

Muchas son las cuestiones que abarca el estudio de la historia de la edición. Desde el movimiento empresarial alrededor del libro hasta los hábitos de lectura, la historia de la edición es un campo de estudio de considerables dimensio- 
nes. En ella se inserta también el análisis del tema que centrará este artículo: la propiedad intelectual. Como objeto de estudio, la propiedad intelectual resulta ser cuestión principal por cuanto supone el fundamento del negocio editorial, por una parte, y el capital de los autores y objeto de su comercio, por otra. Estas páginas pretenden ser tan sólo un primer acercamiento, pero a través de ellas podemos ver cómo, dentro del terreno de la historia de la edición, la propiedad intelectual nos conduce a multitud de aspectos colaterales de enorme importancia: el estatuto jurídico del autor, el funcionamiento empresarial, las relaciones autor-editor, sin olvidar otros aspectos que aquí apenas serán tratados por falta de espacio, pero que son de similar importancia, como las condiciones de vida de los escritores, las manifestaciones artísticas más productivas económicamente, la regulación de las nuevas formas de expresión, etc. ${ }^{1}$.

El concepto de derecho de autor, en el sentido que actualmente manejamos, pudiera inducirnos a error al contemplar la situación en el pasado. Ya a finales de la Edad Media y principios de la Edad Moderna, se concebía tal derecho como un privilegio de los editores, a quienes el autor vendía su obra para siempre y sin más recompensa que lo que ambos acordaran como pago. No existía, por tanto, ningún sentido especial de propiedad del autor acerca de sus escritos, sino que únicamente constituía una forma de expresión de ideas, pero sin el sentido de la originalidad que en nuestros días le atribuimos. Los reyes solían conceder a los impresores, quienes eran los verdaderos protagonistas de la edición, el privilegio de publicar, de ser los dueños de una obra que les había sido vendida, y los conflictos, de plantearse, surgían únicamente por usurpaciones de derechos entre impresores. En función de este criterio nacieron las más antiguas sociedades de impresores, destacando entre todas ellas la Stationers' Company londinense, cuya actividad era un auténtico monopolio, pues nadie podía editar una obra que ya había sido publicada por alguno de sus agremiados ${ }^{2}$. Esta situación, que permaneció durante los años siguientes, comenzó a disolverse en el siglo XVIII, momento en que se individualiza la figura del autor, en que la producción propia comienza a tener un valor por si

1 El presente trabajo forma parte de un estudio para el cual la autora ha recibido una beca postdoctoral financiada por la Comunidad de Madrid y la Unión Europea. Dicho estudio se encuadra en el proyecto de investigación "Historia de la edición española contemporánea, 1836-1936», dirigido por Jesús A. Martínez Martín y realizado en el Departamento de Historia Contemporánea, Facultad de Geografía e Historia (Universidad Complutense de Madrid). En estas páginas, y dada la amplitud del tema, se ha optado por centrarse preferentemente en cuestiones legales y corporativas.

2 En Inglaterra, el primer privilegio fue concedido al impresor real Richard Pynson en 1518. Los privilegios tratados entre los impresores y la Stationers' Company comenzaron a regir en 1556 (vid. Blagden, Charles: The Stationers' Company: a History, 1403-1959, Londres 1960, y PUTNAM, George H.: Books and their makers during the middle ages, 2 vols, Nueva York y Londres 1897). Las mismas fechas, entre los siglos XV y XVI, pueden darse para Francia e Italia.

Hispania, LXII/3, núm. 212 (2002) 993-1020 
misma, y en que empieza a contemplarse la propiedad intelectual como un derecho del creador literario o artístico ${ }^{3}$.

Será en Francia donde más claramente se manifiesten estas nuevas tendencias, con la polémica surgida entre Condorcet (Fragmentos sobre la libertad de prensa) y Diderot (Carta sobre el comercio de librería), el primero abogando por el servicio social de las ideas del intelectual, y el segundo por la intrínseca originalidad de las mismas, y por tanto, por la individualización del intelectual ${ }^{4}$. Unos pocos años antes de la revolución, el Consejo Real ordenó lo que puede ser considerado el primer intento de regulación del derecho del autor en sentido moderno. Se trataba de los decretos de 30 de agosto de 1777, que si bien no afectaban al derecho de autor más que antes de la publicación de la obra, suponían un avance considerable respecto a lo existente. Más tarde, ya en tiempos revolucionarios, se promulgaron dos decretos especialmente interesantes. El primero, de 13-19 de enero de 1791, se refería sobre todo a la propiedad de los espectáculos y representaciones. Más importante para el tema que nos ocupa fue el de 19-24 de julio de 1793, que reconocía la figura del autor como ente independiente y generador de su propia obra, y que también consideraba la importancia de la originalidad de ésta (la cuestión de la originalidad tendrá posteriormente una gran importancia en el tratamiento de los aspectos relativos a la propiedad intelectual). Los decretos de 1793 , además de reconocer al autor y la propiedad sobre su obra, establecían los derechos de sus herederos. De este modo, el autor quedaba desvinculado del impresor. Los países influidos por la cultura francesa (entre ellos el nuestro, que recogió estas premisas, aunque con un mayor grado de prevención) manifestaron en sus respectivas legislaciones los preceptos de los decretos de $1793^{5}$.

Una evolución paralela, aunque con las peculiaridades propias del common law, se dio en los países anglosajones, y en particular en Gran Bretaña. El absoluto predominio de la Stationers' Company comenzó a ponerse en entredicho en el siglo XVII por medio de los numerosos pleitos surgidos entre sus asociados y los nuevos editores e impresores surgidos con el desarrollo cultural y económico. Hasta el momento (y al igual que en Francia y en el resto de Europa), el copyright no protegía la obra en si misma, las ideas que aportaba o su origi-

3 Vid. DRAHOS, Peter: A philosophy of intellectual property (applied legal philosophy), Vermont 1996.

4 Vid. GuIFFreY, Georges: La propriété littéraire au XVIII' siècle, París, 1859.

5 Por lo que respecta a Francia, la bibliografía es amplia. Se seleccionan aquí los artículos y libros más destacados: HESSE, Carla: «Enlightment epistemology and the laws of authorship in revolutionary France, 1777-1798», Representations 30 (1990) pp. 109-137. De la misma autora: Publishing and cultural politics in revolutionary France, 1789-1810, Berkeley 1991. BONCOMPAIN, Jacques: La Revolution des Auteurs. Naissance de la propriété intellectuelle (1773-1815), París 2001. MCCARTHY, Joseph A.: «Rewriting the role of the writer: on the 18th century as the age of author», en Leipziger Jabrbuch zur Buchgeschicbte, (Leipzig) 5 1995, pp. 13-18. Para Alemania, véase: WOODMANSEE, Martha: "The genius and the copyright: economic and legal condition of the emergence of the author", Eighteenth-Century Studies (Londres) 17 (1984), pp. 425-448.

Hispania, LXII/3, núm. 212 (2002) 993-1020 
nalidad, sino simplemente el derecho de copia de un determinado impresor ${ }^{6}$. Las cosas empezaron a cambiar con el Statute of Anne (1710), mediante el cual los miembros de la Stationers' Company empezaron a perder sus privilegios. Si bien no estableció la noción de propiedad literaria, representó un momento muy importante en el proceso de transformación y de toma en consideración de la figura del autor?.

Ya en el siglo XVIII había quedado definida la concepción romántica de la autoría como la originalidad de la creación individual. De este modo, el autor sería un participante principal en el proceso de difusión de las ideas, dueño de unas técnicas y conocedor de unos mecanismos que daban lugar a la emergencia de una obra única ${ }^{8}$. Esa noción del autor-creador tenía, por otra parte, una muy adecuada adaptación al sistema económico en tanto que el autor aparecía como propietario. Era igualmente favorable a los editores y libreros por cuanto la positivación de tal derecho daba cobertura legal a sus atribuciones. La clave de la capacidad de acción tanto de autores como de editores iba a radicar en la legislación, pues el derecho de autor se había convertido en un instrumento legal para regular las condiciones de la producción cultural.

\section{LA CONVENCIÓN DE BERNA}

Ya en la época contemporánea se inició un proceso de avance imparable en el reconocimiento del derecho del autor en cuanto tal. El acuerdo de mayor significación al respecto de la materia que nos ocupa comenzó a gestarse en la Asociación Literaria Internacional, precursora de la Asociación Literaria y Artística Internacional (ALAI), cuyo primer presidente sería Víctor Hugo. La sociedad se había fundado en 1878 proponiéndose la defensa de los derechos de la propiedad intelectual en todos los países en los que pudiera tener influencia9. Desde muy temprano había celebrado reuniones para determinar su forma de actuación. En el congreso celebrado en Roma en 1882, la ALAI decidió congregar en Berna a un número importante de escritores, editores, artistas, universitarios y demás personas vinculadas al mundo de la producción artística e

6 Patterson, Lewis R.: Copyright in Historical Perspective, Nashville 1968, pp. 51-55.

7 ROSE, Mark: Authors and owners. The invention of copyright, Cambridge (Mass.) y Londres 1993, p. 48. Vid. además: PATTERSON, Angela: Censorship and interpretation: the condiction of writing and reading in early modern England, Madison 1984. RANSOM, Howard: The first copyright statute: an essay on an act for the encouragement of learning 1710, Austin 1956. Acerca de los Estados Unidos: ABRAMS, Henry B.: "The historic foundation of American copyright law: exploding the myth of common law copyright», en Wayne Law Review (Wayne) 29 (1983) pp. 1119-1191.

8 WOODMANSEE, Martha: «On the Author Effect: Recovering Collectivity», en WOODMANSEe, Martha y JASZI, Peter (editores): The construction of authorship. Textual appropiation in law and literature, Londres 1994, p. 16. Vid. también ABRAMS, Michael H. The mirror and the lamp, Oxford 1953.

9 Vid. Association littéraire et artistique internationale. Son bistoire-Ses travaux, 1878-1889, París 1889.

Hispania, LXII/3, núm. 212 (2002) 993-1020 
intelectual con objeto de establecer las bases de un convenio que sirviese de guía para la protección de la propiedad intelectual. La conferencia se celebró en septiembre de 1883. Dos reuniones más continuaron su labor (1884 y 1885), observándose en sus resoluciones una muy clara influencia de la ley francesa para la protección intelectual, que también había determinado la legislación de los países de su área de influencia. Se trataba de la ley de 19 a 24 de julio de 1793, modificada por los decretos de 22 de marzo de 1805 , de 19 de marzo de 1810 , de 3 de agosto de 1844 , por los decretos de 28 a 31 de marzo de 1852 , de 16 de mayo de 1866 y de 14 de julio de $1866^{10}$. Una vez establecidas las bases del acuerdo, los países interesados se reunieron en Berna en 1886 para firmar el acuerdo de creación de una unión internacional para la protección de la propiedad intelectual. La rúbrica se estampó el 9 de septiembre. España, que no había participado en las reuniones previas, fue uno de los países firmantes del Convenio de Berna. Además de nuestro país, participaron en el acuerdo Alemania, Bélgica, Gran Bretaña (representando también a Australia, a Canadá, a Nueva Zelanda, a sus provincias de África del Sur y a la India), Francia, Haití, Liberia, a Confederación Helvética, Italia y Túnez.

El Convenio de Berna tenía como objetivo garantizar una serie de protecciones a la propiedad intelectual entre los países firmantes, y obligar a éstos a que regulasen su propia legislación en función de unos principios básicos establecidos en el acuerdo, aunque nunca tratando de prevalecer sobre la legislación interna acerca de estas materias. Su principal objetivo venía señalado en el artículo $2^{\circ}$ que apuntaba a que los autores pertenecientes a cualquiera de los países de la unión, o sus herederos, gozarían en las otras naciones de los derechos que las leyes respectivas concedieran en el presente o en el futuro a las obras publicadas o no en dichos países. Pese a sus intenciones, el Convenio de Berna no elaboró ninguna definición de la propiedad intelectual, sino que más bien se ocupó de definir la expresión 'obra literaria y artística' y se centró especialmente en los derechos de autor, en su limitación en el tiempo y en las agresiones de que tales derechos pudieran ser objeto (por ejemplo, las traducciones ilícitas, las copias, etc.). El tratado definiría así su objeto:

«L'expression 'oeuvres littéraires et artistiques' comprend les livres, brochures ou tous autres écrits; les oeuvres dramatiques ou dramatico-musicales, les compositions musicales avec ou sans paroles; les oeuvres de dessin, de peinture, de sculpture, de gravure; les lithographies, les illustrations, les cartes géographiques; les plans, croquis et ouvrages plastiques relatifs à la géographie, à la topographie, à l'architecture ou aux sciences en général; enfin toute production quelconque du domaine littéraire, scientifique ou artistique, qui pourrait être publiée par n'importe quel mode d'impression ou de reproduction".

10 Vid. BerTRAND, André: Le droit d'auteur et les droits voisins, París 1991 y GervaIs, Denis: La notion d'oeuvre dans la Convention de Berne et en droit comparé, Ginebra 1998. 
De este modo quedaba asegurado el amparo a obras no sólo literarias, sino las que se manifestasen en otros soportes, dejando, además, abierta la puerta para posibles ampliaciones en este derecho. Una vez más, la influencia de la legislación francesa se manifestaba con toda nitidez ${ }^{11}$.

Por lo que respecta a la obligatoriedad de la inscripción en cualquier tipo de registro, el Convenio no indicaba que tal requisito fuese indispensable, sino que únicamente bastaba «que su nombre esté indicado en la obra en la forma acostumbrada». Sin embargo, de poco servía esta concepción más laxa del valor de la prueba, pues en el párrafo siguiente de dicho artículo 11 remitía a las exigencias de la legislación nacional al respecto. Una de las cuestiones más interesantes de las que quedaban reguladas por el Convenio de Berna fue la creación de una 'Oficina de la Unión Internacional para la protección de las obras literarias y artísticas', sufragada por todos los países firmantes y bajo la administración de la Confederación Suiza. Sus funciones quedaron recogidas en el punto $5^{\circ}$ del Protocolo Final:

«Dicha oficina reunirá las noticias de todo género relativas a la protección de los derechos de autor sobre sus obras literarias y artísticas, las coordinará y las hará publicar», «Procederá a los estudios de utilidad común relativos a los países unidos, y redactará, sirviéndose de los documentos puestos a su disposición por las diversas administraciones, un periódico en lengua francesa, que trate de asuntos concernientes al objeto de la Unión», «La Oficina internacional deberá siempre prestarse a facilitar a los miembros de la Unión cuantos antecedentes necesiten respecto a las cuestiones relativas a la protección de las obras literarias y artísticas», "La administración del país donde deba celebrarse una conferencia, preparará sus trabajos ayudada por la Oficina internacional».

El Convenio de Berna preveía la posibilidad de revisiones sucesivas, como de hecho así sucedió en la conferencia celebrada en París en 1896, en la cual se concretaron algunos aspectos del tratado acordado diez años antes. Más trascendencia tuvo la conferencia celebrada en Berlín en 1908, que dio lugar a una nueva redacción del tratado que se ratificó el 7 de septiembre de 1910. Aunque una vez más se señalaba que el marco de referencia para la protección de un autor en un país firmante del acuerdo era la legislación al respecto, se apuntaba que «el goce y ejercicio de estos derechos no se subordina a ninguna formalidad; este goce y este ejercicio son independientes de la existencia de protección en el país de origen de la obra» ${ }^{12}$. El artículo 6 del tratado ofrecía

11 Vid. a este respecto DesBoIs, Henri: Le droit d'auteur en France, París 1973. Con respecto a las deliberaciones y resoluciones de la Convención de Berna: Actes de la $3^{e}$ Conférence internationale pour la protection des oeuvres littéraires et artistiques réunie à Berne du 6 au 9 septembre 1886, Berna 1886; igualmente, vid. RICKETSON, Samuel: The Berne Convention for the Protection of Literary and Artistic Works: 1886-1986, Londres 1987.

12 «Convenio revisando el de Berna, firmado en Berlín el 13 de noviembre de 1908 y ratificado el 7 de septiembre de 1910», Gaceta, 9-9-1910. 
protección a los autores que no pertenecieran a alguno de los países de la Unión y que publicaran sus obras en ellos, quedando protegidos por sus respectivas legislaciones. Una de las más importantes cuestiones que los anteriores convenios no recogían era la duración de la protección que se prestaba, y que según esta nueva redacción comprendía la vida del autor y cincuenta años después de su muerte. La protección era más extensa en la legislación española, alcanzando los ochenta años tras el fallecimiento del autor. Otro de los asuntos especialmente tratados en Berlín fue la regulación de los textos aparecidos en publicaciones periódicas. Aunque el asunto ya había sido desarrollado en París, la Conferencia de Berlín consolidó las posiciones oficiales al respecto, garantizando al autor la última decisión acerca de si dichos textos podrían reproducirse en el extranjero o en formatos diferentes al inicialmente concebido (artículo 9). Por último, el artículo 22 dejaba abierta la posibilidad de que cada país estableciese acuerdos bilaterales con otro, sin perjuicio de los compromisos aceptados en las conferencias internacionales.

Dado que el tratamiento pormenorizado de estos acuerdos podría requerir demasiado tiempo, concluiremos haciendo referencia a la reunión mantenida en Roma en 1928 que procedió a la actualización de los tratados anteriores. Se reforzó la posición el autor otorgándole un poder de disposición mayor sobre su obra, tal y como recogía el artículo $6^{\circ}$ bis del tratado:

«1) Independientemente de los derechos patrimoniales del autor, y lo mismo después de la cesión de dichos derechos, el autor conserva el derecho de reivindicar la paternidad de la obra, así como el derecho de oponerse a toda deformación, mutilación u otra modificación de dicha obra, que fuere perjudicial a su honor o a su reputación; 2) Queda reservado a la legislación nacional de los países de la Unión el fijar las condiciones para ejercitar estos derechos. Los medios para salvaguardarlos serán reglamentados por la legislación del país donde se reclame la protección» ${ }^{13}$.

\section{LA LEGISLACIÓN EN ESPAÑA}

En España tuvo lugar el primer reconocimiento de los derechos del autor en tiempos de Carlos III, quien decretó el carácter vitalicio de los derechos de autor y la potestad de éste de traspasar tales derechos a sus herederos ${ }^{14}$. Los

13 «Ley aprobando el Convenio para la protección de obras literarias y artísticas, firmado en Roma el 2 de junio de 1928», ratificado el 21 de julio de 1932 y publicado en la Gaceta de 5 de agosto de 1932. «Convenio de Berna, para la protección de las obras literarias y artísticas del 9 de septiembre de 1886, revisado en Berlín el 13 de noviembre de 1908, y en Roma el 2 de junio de 1928", Gaceta, 25-4-1933.

14 Así decía el título $8^{\circ}$ de la ley 25 de la Novísima Recopilación: «He venido en decretar que los privilegios concedidos a los autores no se extingan por su muerte, sino que pasen a sus herederos, como no sean comunidades o manos muertas, y que a estos herederos, se les continúe el privilegio

Hispania, LXII/3, núm. 212 (2002) 993-1020 
liberales de Cádiz, recogiendo el ejemplo revolucionario francés, decretaron el 10 de junio de 1813 que sólo los autores o las personas por ellos autorizadas podían imprimir sus obras, y sus herederos durante diez años. El 5 de agosto de 1823, en los momentos finales del segundo periodo constitucional, las Cortes lograron la sanción real para un proyecto que también reconocía el principio de la propiedad de los autores, aunque no se profundizó en las derivaciones de este derecho. Los acontecimientos políticos posteriores despojaron de cualquier efecto a esta ley. Más tarde, una vez pasados los convulsos primeros momentos de las luchas para establecer el régimen constitucional en España, en 1834 se publicó la real orden de 4 de enero que instituyó el principio por el cual la propiedad intelectual pertenecía a los autores de por vida y a sus herederos pasados diez años de la muerte del autor. La protección a los autores se concluyó en estos primeros momentos del régimen liberal español con la real orden de 5 de mayo de 1837, que abundaba en lo anteriormente mencionado.

La primera ley que reconoció de forma extensa y clara los derechos del autor fue la publicada el 10 de junio de 1847 , aunque se habían redactado proyectos desde $1840^{15}$. El proyecto elaborado por el gobierno fue presentado ante las dos Cámaras por el Ministro de Comercio, Instrucción y Obras Públicas, Mariano Roca de Togores. Las palabras preliminares del texto abogaban por la propiedad del autor como si se tratase de cualquier otra forma de propiedad, señalando la necesidad de su protección para el progreso del país y dándole al autor el poder total de disponer de su producción como mejor le conviniera, poniendo fin de esta manera a los privilegios de impresión. No es de extrañar esta actitud en los políticos de la primera mitad del siglo XIX, la mayoría de ellos vinculados al mundo literario de una u otra forma. Se trataba, en la medida de lo posible, de dar un carácter si no profesional, al menos más sólido a la labor del creador intelectual. Asimismo, para los hombres del XIX, la confección de esta ley suponía un respaldo a las actividades intelectuales. Herederos de la Ilustración y sus programas de educación y progreso, la idea de estos políticos se basaba en el deseo de proteger la producción intelectual en tanto que medio para educar a la población. Sin embargo, y precisamente por esa preocupación pedagógica, establecieron una limitación en la ley a la libre disposición de la propiedad literaria y artística:

«Mas en este punto se tropieza con una dificultad gravísima, la mayor quizá que se ofrece en esta materia. Desde el momento en que se publica una obra, ya sale hasta cierto punto de la jurisdicción privativa del autor y se hace patrimonio de la sociedad respecto de su uso y aprovechamiento. Un libro, por

mientras lo soliciten, por la atención que merecen aquellos literatos, que después de haber ilustrado su patria no dejan más patrimonio a sus familias que el honrado caudal de sus propias obras y el estímulo de imitar su buen ejemplo».

15 Expediente fechado en noviembre de 1845 que recoge algunos de estos proyectos en el Archivo del Registro General de la Propiedad Intelectual. Un análisis jurídico de la ley de 1847 y de la posterior de 1879 en MARCo MOLINA, Juana: La propiedad intelectual en la legislación española, Madrid 1995.

Hispania, LXII/3, núm. 212 (2002) 993-1020 
ejemplo, no puede equipararse con una alhaja que se deja a los herederos y a quienes es lícito sepultar o destruir a su antojo, cual pudo hacerlo su primitivo dueño; el Estado mismo tiene un derecho a que se le prive de los beneficios de una obra por incuria, por capricho, o tal vez por dañada voluntad de aquellos en quienes haya recaído la facultad de disponer de ella. Razón por la cual los legisladores de otros países, y a su vez el gobierno en el proyecto que presenta, se han visto precisados a templar la rigidez del principio de la propiedad literaria, no igualándola cumplidamente con las demás, en cuyo caso hubiera bastado comprenderla en las reglas comunes del derecho civil, sino antes bien sujetándola a una legislación particular, como lo es su índole y naturaleza» ${ }^{16}$.

Es decir, se reconocía a la producción intelectual una suerte de función social, alumbradora de la cultura nacional. Fue este aspecto, precisamente, el que prevaleció a la hora de defender la ley de propiedad literaria como una ley independiente de las leyes comunes acerca de la defensa de la propiedad. En el Congreso, Antonio Ríos Rosas insistió en ello frente al diputado Gómez de la Serna:

«...la propiedad literaria es una propiedad eminentemente excepcional, y tiene de particular la circunstancia de que en el momento que entra en el dominio público el pensamiento de un autor por medio de las formas que le da, del estilo y de la imprenta, desde aquel momento se constituye la propiedad literaria. De manera que sucede con esto una cosa inversa de lo que sucede con las demás propiedades. El pensamiento es propiedad del autor; pero desde el momento en que éste lo emite por medio de la palabra, de la escritura o de la prensa, cae en el dominio público y se hace del de cuantos le escuchan, le escriben o le leen. Ésta es verdaderamente la naturaleza de la propiedad literaria...»17.

Con más claridad se manifestaron otros miembros de la comisión del Congreso como el diputado García Goyena: «La propiedad literaria, señores, es una ficción, una creación del legislador fundada en motivos de justicia respecto del autor y en motivos de conveniencia respecto del público» ${ }^{18}$. Ante esta ambigüedad, algunos diputados consideraron la posibilidad de incluir la defensa de la propiedad de los autores entre la protección que se otorgaba a los inventos y fórmulas médicas. Sin embargo, la simple sugerencia de equiparar los produc-

16 Diario de Sesiones de las Cortes, Senado, «Proyecto de ley sobre propiedad literaria», palabras preliminares del Ministro de Instrucción Pública (legislatura de 1847, sesión del 20 de febrero de 1847). Las comisiones encargadas de este proyecto en ambas Cámaras estaban formadas también por ilustres escritores: Javier de Burgos, Marqués de Vallgornera, Florencio García Goyena, Antonio Alcalá Galiano y el Marqués de Falces (Senado); Francisco Martínez de la Rosa, Lorenzo Arrazola, Antonio de los Ríos Rosas, Andrés Leal, Fernando Álvarez y Diego Coello y Quesada (Congreso). Todo el procedimiento en Archivo de la Presidencia del Gobierno, Biblioteca 3293/16 (Senado) y 3371 (Congreso).

17 Diario de Sesiones de las Cortes, Congreso, legislatura de 1847, sesión de 17 de abril de 1847.

18 Diario de Sesiones de Las Cortes, Congreso, legislatura de 1847, sesión del 10 de marzo de 1847. 
tos del entendimiento con los adelantos materiales espantó a los miembros de la comisión.

Sorprende a cualquiera que se acerque a esta ley su propia enunciación: «Ley sobre la propiedad literaria». En efecto, bajo el epígrafe de propiedad literaria, la ley trataba también de proteger las obras escultóricas y pictóricas. Esta ampliación del término implicaba el total predominio de la literatura sobre las demás artes en nuestro país, y aunque el hecho fue señalado por algunos diputados, no se cambió el nombre al proyecto. Especial interés tiene la observación efectuada por el diputado Vázquez Queipo acerca de la extensión de la ley a los territorios coloniales, a Cuba, dados los ataques que contra los intereses de los autores y las publicaciones oficiales se cometían. Las ediciones fraudulentas en América serán un tema recurrente en el sector editorial español durante los siglos XIX y XX, problema que se tratará de atajar, primero, extendiendo la legislación a la América española, y después, estableciendo tratados bilaterales de protección. De hecho, el Ministerio de Gracia y Justicia dictó el 7 de febrero de 1848 una real orden por la cual se imponía la ley de propiedad literaria en las propiedades españolas de Ultramar.

Tal y como salió de las Cámaras, la ley definía el objeto de su protección de la siguiente forma:

«Se entiende por propiedad literaria para los efectos de esta ley el derecho exclusivo que compete a los autores de escritos originales para reproducirlos o autorizar su reproducción por medio de copias manuscritas, impresas, litografiadas, o por cualquiera otro semejante» (artículo $1^{\circ}$ ).

Asimismo, el artículo $2^{\circ}$ hacía residir el derecho en la persona del autor y sus herederos por el plazo de 25 años, superando los diez años de la anterior disposición. Los beneficiarios eran tanto los autores literarios y científicos como los traductores, compositores musicales, calígrafos, dibujantes, pintores y escultores (artículo $3^{\circ}$ ). Incluía esta ley una disposición muy importante que constituía el fundamento de la protección que se otorgaba, y suponía la base para emprender acciones legales en los juzgados de primera instancia, tal y como establecía el artículo 24. Decía la ley en su artículo 13 lo siguiente:

«Ningún autor gozará de los beneficios de esta ley si no probase haber depositado un ejemplar de la obra que publique en la Biblioteca Nacional, y otro en el Ministerio de Instrucción Pública antes de anunciarse su venta. Si las obras fueren publicadas fuera de la provincia de Madrid cumplirán sus autores o editores con la obligación que les impone este artículo, probando haber entregado los dos ejemplares al jefe político de la provincia, el cual los remitirá al Ministerio de Instrucción Pública y a la Biblioteca Nacional».

La real orden de 1 de julio de 1847 estableció los mecanismos para llevar a la práctica estas disposiciones del artículo 13, completada después por la real 
orden de 1 de marzo de 1856. Preludio del Registro de la Propiedad Intelectual (que en aquellos tiempos ya contaba con un amplio recorrido en países como Francia), la entrega de ejemplares se recogería en las leyes posteriores, y fue objeto de crítica por parte de los editores, que veían en ella un gasto superfluo y un trámite engorroso, y por parte de los autores, quienes entendían la propiedad intelectual como algo cuyo reconocimiento estaba más allá de la simple constatación burocrática, dentro de una concepción del trabajo intelectual que poco tenía de profesional y todo de artístico y sublime.

Juana Marco Molina, principal especialista en estas cuestiones, ha señalado que si bien esta ley presentaba rasgos de modernidad, aún mantenía aspectos que recordaban demasiado a los antiguos privilegios de los impresores:

«Así, no consigue todavía abstraer el derecho sobre la obra como creación inmaterial, del derecho de propiedad ordinaria que recae sobre el objeto físico que la representa. Es por ello que, al igual que los antiguos privilegios, en realidad sólo protege plenamente a la obra escrita (artículo $1^{\circ}$ de la Ley) en forma de libro. Y sólo en definitiva por falta de abstracción respecto a un objeto material se explica también que el derecho de reproducción de la obra plástica se asigne, no a su autor, sino al adquiriente del original de la misma; y que la mera posesión de un manuscrito constituyese título suficiente para ostentar el derecho de imprimirlo en exclusiva»19.

Pero no sólo la acepción jurídica de la propiedad intelectual se vio afectada por esa carencia, sino también la misma consideración social que los impulsores del proyecto dieron a la propiedad intelectual. La consecuencia más palpable de esta aparente contradicción entre 'las más altas producciones del espíritu' y su nulo rendimiento económico fue la retórica vacía que rodeó siempre el mundo de la producción intelectual, y en particular, al libro; una retórica que presidió las declaraciones de los gobiernos y que escondía, a duras penas, las reclamaciones monetarias de editores y autores. Los avances más significativos producidos por esta ley vinieron por el reconocimiento de los derechos de los autores, y sobre todo de los autores de obras dramáticas y musicales, quienes dispusieron de la facultad de decidir acerca de cómo, cuándo y por quién habrían de ser representadas sus obras.

La ley de 1847 se vería suplantada por la legislación promulgada durante la Restauración, que sería el fundamento de la regulación de esta materia hasta la ley de 1987. Dicha legislación estaba compuesta por la ley de 10 de enero de 1879 y el reglamento dictado el 3 de septiembre de 1880, que la ponía en práctica. Su promulgación tampoco fue igualmente recogida por todos los sectores implicados en ella, pues si bien entre algunos autores cayó con agrado puesto que les reconocía un extenso número de años como titulares de sus obras, entre los editores no gustó en absoluto. De hecho, dio pie a la organiza-

19 MARCo MolinA, Juana: La propiedad intelectual..., p. 22. 
ción corporativa de este sector, principalmente en Madrid y en Barcelona, como se verá más adelante. Los puntos más conflictivos desde la perspectiva de los editores se centraron alrededor los derechos de autor, la inscripción en el Registro de la Propiedad Intelectual (creado precisamente por esta ley) y la obligatoriedad para el editor de donar varios ejemplares de las obras publicadas a diversas instituciones públicas. Anteriormente, en 1876, Gaspar Núñez de Arce y Emilio Castelar habían presentado al Congreso un proyecto elaborado por el jurista Manuel Danvila Collado que pretendía reformar la ley de 1847 incluyendo el derecho perpetuo de los autores a disponer de su obra. Los ministros de Justicia y Fomento se opusieron a tal principio y frenaron el camino al proyecto de Danvila ${ }^{20}$.

Un nuevo proyecto de ley entró en las Cámaras con la denominación de «Proyecto de ley sobre propiedad literaria, artística y científica», aunque dicha denominación fue sustituida por la comisión de senadores encargados de su estudio por la de «propiedad intelectual» aduciendo que:

«...la comisión juzga muy preferible emplear en el título de la ley la palabra intelectual, que comprende las producciones literarias, artísticas y científicas, pues a consecuencia de llamar siempre de propiedad literaria a las leyes y a los convenios internacionales sobre esta materia, se ha descuidado, fijando especialmente la atención en las letras, el atender cual se debía en las unas y en los otros a las ciencias y a las artes» 21 .

Esta decisión denota un talante diferente entre los legisladores. Los hombres de la Restauración, muchos de ellos profesionales técnicos, con menores vinculaciones literarias que los de generaciones anteriores, hicieron hincapié en otras formas de la producción intelectual. Aun así, la consideración de la propiedad intelectual como una propiedad diferente fue objeto de críticas por parte del Conde de Casa Valencia, quien demandó que lo lógico es que se rigiera por el derecho común, pues lo que se estaba pretendiendo era recortar la libertad del autor para negociar libremente con su obra. A sus interpelaciones respondió el Marqués de Valmar señalando que

«Desde luego la propiedad intelectual tiene dos aspectos diferentes que no pueden desconocerse: el aspecto del lucro y el de la gloria; cuando la propiedad común u ordinaria no tiene más que uno. Se trata pues de dos propiedades diferentes...».

20 Vid. Danvila, Manuel: La propiedad intelectual, Madrid 1882 y Archivo de la Presidencia del Gobierno, Biblioteca, 3478/9, $3483 / 9$ y 3484/9. Núñez de Arce y Castelar fueron miembros del Comité de Honor de la Asociación Literaria y Artística Internacional, fundada por Víctor Hugo. Núñez de Arce sería nombrado poco después presidente de la Asociación de Escritores y Artistas Españoles.

21 Diario de Sesiones de las Cortes, Senado, legislatura de 1878, sesión del 16 de diciembre de 1878. La comisión del Senado estuvo formada por el Marqués de San Gregorio, Agustín Pascual, el Conde de Tejada de Valdosera, el Conde de Casa Galindo, Escosura (sustituido después por el Marqués de Valmar), Oliván (sustituido después por el Marques de Heredia) y Federico de Madrazo.

Hispania, LXII/3, núm. 212 (2002) 993-1020 
Más adelante abundaría en tales disimilitudes del siguiente modo:

«Ya creo haber dicho que el monopolio de la propiedad intelectual es contrario a la civilización universal, y por eso se establece esa diferencia. La falta de propagación dañaría a la gloria misma del autor y sería ciertamente contraria a los nobles fines de su voluntad y de su entendimiento» 22 .

Aunque se constituyó una comisión mixta de senadores y diputados, apenas hubo debate en el Congreso pues dicha comisión recomendó la aprobación urgente de la ley, hecho que se produjo el 19 de diciembre de 1878 , y se sancionó y publicó como ley el 26 de ese mes de diciembre de 1878.

Sin entrar en disquisiciones acerca de qué concepto habría de ser aplicado a la propiedad intelectual, es decir, sin definirla ni precisar matizaciones acerca de sus características particulares con respecto a otras formas de propiedad, y sobre todo, con respecto a las formas materiales de posesión, la ley de 1879 se limitaba a señalar que sobre ella habría de aplicarse el derecho común para todo tipo de conflictos, y del derecho común se derivaban sus regulaciones ${ }^{23}$. La ley abarcaba las diversas manifestaciones y expresiones del pensamiento y del arte: producciones literarias y ensayísticas, discursos parlamentarios, traducciones, obras dramáticas y musicales, periódicos y colecciones, pinturas y esculturas, así como distintas situaciones como la existencia de obras póstumas o de obras anónimas. Del mismo modo, se regulaba sobre la aplicación de estas normas y el derecho internacional, sobre el cumplimiento de la normativa en Ultramar y sobre el proceso que se habría de seguir para adecuarse a la nueva legislación desde las prescripciones de la ley de 1847.

El artículo 33 de la ley creaba el Registro de la Propiedad Intelectual en el seno del Ministerio de Fomento, del que dependerían los registros abiertos en las bibliotecas provinciales y en los institutos de enseñanza secundaria. En estos registros habrían de inscribirse no sólo las obras literarias, sino también todas 1878

22 Diario de Sesiones de las Cortes, Senado, legislatura de 1878, sesión del 16 de diciembre de

23 Detrás de estas consideraciones se hallaba la indefinición del concepto de propiedad intelectual en la legislación española. La caracterización como 'propiedad especial', junto con las aguas y los minerales, no quedaría definida hasta el Código Civil de 1889. Hasta ese momento, la ley preveía la posesión sobre cosas materiales. La dogmática alemana, más avanzada a este respecto, hablaba ya del 'derecho sobre bienes inmuebles' (Josef Kohler) o del derecho de autor como uno de los 'derechos de la personalidad' (Otto von Gierke). A este respecto, vid. MARco MolinA, Juana: «Bases históricas y filosóficas y precedentes legislativos del derecho de autor», en Anuario de Derecho Civil (Madrid) tomo 47, fascículo $1^{\circ}$ (1994), pp. 121-208. Decía el artículo $1^{\circ}$ de la ley de 1879: «La propiedad intelectual comprende, para los efectos de esta ley, las obras científicas, literarias o artísticas que pueden darse a la luz por cualquier medio». Fundaba el derecho, por tanto, en la difusión, el conocimiento público de la autoría. De este modo, la publicación (la transformación material) permitiría la máxima difusión, aunque también se reconocieran otras formas de reproducción (vid. artículo $8^{\circ}$ de la Ley). 
las producciones artísticas, cartográficas o arquitectónicas, con la obligatoriedad de entregar tres ejemplares de las obras inscritas, una de las cuales iría a la biblioteca provincial, instituto o registro del Ministerio, otro al Ministerio de Fomento y el tercero a la Biblioteca Nacional. Las obras musicales o dramáticas que hubieran sido representadas en público sólo estaban sujetas a depositar un ejemplar; las producciones artísticas (esculturas, pinturas o similares) estaban dispensadas de esta obligación. El trámite era complicado y terminaba con el pago del correspondiente impuesto, del que se veían exentos los autores de obras científicas, literarias o artísticas, pero no los editores o representantes teatrales, y tampoco los herederos de dichas obras científicas, literarias o artísticas. El Registro se convertía así en la clave del reconocimiento de la propiedad de toda producción de carácter intelectual, y suponía un claro avance con respecto a la situación anterior. Era el fundamento sobre el que pivotaba cualquier reclamación, pues la inscripción era obligatoria si se pretendía obtener protección al respecto. La ley autorizaba a reimprimir toda obra que no hubiera sido inscrita en el Registro durante los diez años siguientes al término del periodo de inscripción, aunque aún le quedaba al dueño la posibilidad de anotarla en el Registro tras estos diez años, pasando al dominio público si tal circunstancia no acontecía (artículos 39, 40 y 42).

Una de las más importantes aportaciones de la ley de 1879 fue la ampliación temporal del reconocimiento de derechos a los herederos. El artículo $6^{\circ}$ señalaba lo siguiente:

\footnotetext{
«La propiedad intelectual corresponde a los autores durante su vida, y se transmite a sus herederos, testamentarios o legatarios, por el término de ochenta años. También es transmisible por actos entrevivos, y corresponderá a los adquirientes durante la vida del autor, y ochenta años después del fallecimiento de éste si no deja herederos forzosos. Mas, si los hubiere, el derecho de los adquirientes terminará veinticinco años después de la muerte del autor, y pasará la propiedad a los referidos herederos forzosos por tiempo de cincuenta y cinco años».
}

La fórmula era muy favorable a los autores, particularmente por cuanto ponía a salvo sus producciones y reconocía los derechos de sus herederos, pero no tanto a los editores, quienes se consideraban gravemente perjudicados por los veinticinco años de posesión que les otorgaba la ley, perdiendo sus prerrogativas ante los herederos al transcurrir este periodo de tiempo. Desde su punto de vista, esta situación planteaba de forma muy clara que no se consideraba a la propiedad intelectual como a cualquier otra forma de propiedad, la cual se adquiere para siempre. Aparte de las protestas de los editores, con esta disposición la ley pretendía proteger las obras de los autores españoles en el extranjero, y en especial en América del Sur, donde tantas publicaciones de autores españoles aparecían de forma clandestina. Si semejante circunstancia se producía con autores vivos, la situación era claramente escandalosa con los herederos 
de autores fallecidos, los cuales se encontraban con enormes dificultades para reclamar sus derechos.

El decreto que ponía en aplicación esta ley de 1879 fue promulgado el 3 de septiembre de 1880 y en él se detallaban las líneas generales esbozadas anteriormente. El decreto comenzaba estableciendo qué es objeto de protección:

«Se entenderá por obras, para los efectos de la Ley de Propiedad Intelectual, todas las que se producen y puedan publicarse por los procedimientos de la escritura, el dibujo, la imprenta, la pintura, el grabado, la litografía, la estampación, la autografía, la fotografía, o cualquier otro de los sistemas impresores o reproductores conocidos o que se inventen en lo sucesivo" (artículo $1^{\circ}$ ).

En el artículo siguiente se describe la figura del autor, haciendo una interesante observación al declarar que:

«se considerará autor, para los efectos de la Ley de la Propiedad Intelectual, al que concibe y realiza alguna obra científica y literaria, o crea y ejecuta alguna artística, siempre que cumpla las prescripciones legales».

El interés de este artículo va más allá de lo meramente orientativo, pues de forma clara se reconoce al autor como un profesional, dueño de su producción en tanto que ésta pueda ser contemplada por la legislación. No se trata solamente de escribir, pintar o realizar cualquier otra labor de tipo artístico, sino hacer patente de cara a la sociedad la autoría de tal producción, esperando de ese reconocimiento tanto la obtención de unos beneficios económicos como la protección legal en caso de apropiación indebida. De este modo, la tarea del escritor o del artista salen del terreno de la bohemia para entrar en el de la profesionalización, al conllevar para ellos mismos una serie de obligaciones legales. En algunos casos, y siempre que la obra hubiera sido adquirida por un comprador, esas obligaciones pasarían a corresponder al adquiriente, generalmente al editor. Dicha circunstancia no oscurece la distinta apreciación que mediante esta legislación se obtiene de la figura del autor en cualquiera de sus manifestaciones.

El Reglamento de 1880 profundizaba en las disposiciones de la ley de 1879 por lo que respecta al Registro de la Propiedad Intelectual. En el Título V recogía el procedimiento que habría de emplearse para la inscripción que, además de lo señalado anteriormente, obligaba a registrar los datos completos de las obras: quién la inscribe, el título, el autor, el tipo de producción intelectual, el editor, el lugar y la fecha de la publicación etc. Igualmente, se marcaba un plazo de un año para la inscripción de la obra una vez finalizada ésta o vendida a un adquiriente. Este plazo fue modificado por un real decreto de 5 de enero de 1894, reduciéndolo a seis meses, con el consiguiente peligro de que las obras pasasen a dominio público. Esta disposición no gustó en absoluto a los editores, los cuales manifestaron públicamente su discrepancia y lograron, algunos años después (junio de 1904), la derogación del decreto por parte del 
Ministerio de Instrucción Pública ${ }^{24}$. La Gaceta del 11 de abril de 1910 publicó un real decreto que ampliaba excepcionalmente a seis meses el plazo del que se disponía para inscribir las obras que hasta el momento no habían sido consignadas en el Registro de la Propiedad Intelectual ${ }^{25}$.

\section{LA SITUACIÓN DE LOS AUTORES}

Los autores españoles, al igual que los del resto de Europa, comenzaron a asumir la función de artistas siguiendo el mismo proceso que el romanticismo había impuesto en el mundo del arte. Sin embargo, la capacidad para articular sus demandas de forma coherente andaba a la zaga de países como Francia, pionera en este aspecto. Se caracterizaba su situación por una relación individual con el editor o impresor, basada en la inseguridad para ambos, pero especialmente, como es obvio, para el autor ${ }^{26}$. Los autores solían vender sus obras otorgando al editor o al impresor la propiedad absoluta y para siempre del texto, de ahí que cuando éste tenía éxito, quien se enriquecía era el comprador y nunca el autor. Ése fue el caso estudiado por Jesús Martínez para la relación entre Zorrilla y el editor Delgado. Zorrilla vendía al editor todas sus producciones $\mathrm{y}$, por distintas circunstancias, vivía siempre a cuenta. Cuando en 1844 hizo la pertinente operación con la obra teatral Don Juan Tenorio, ninguno de los dos podía sospechar el inmenso éxito de la misma, y por consiguiente, la gran cantidad de dinero que ganó Delgado, la misma que perdió el autor. La ley de 1847 no sirvió de gran cosa a Zorrilla, quien en sus Recuerdos expone cómo tuvo que dirigirse al gobierno, dada su calamitosa situación económica, para que le proveyera de algún sustento. Señala Jesús Martínez en su estudio que el tipo más común de contrato entre un editor como Delgado y los autores establecía la cesión absoluta de los derechos del autor, incluyendo también las posibles atribuciones de los herederos. De este modo, los sucesores quedaban invalidados para siempre a la hora de hacer cualquier reclamación; en el caso de las obras teatrales, la situación era similar: también se perdían los derechos para los herederos en todos los teatros del Reino y Ultramar, salvo los de Madrid.

24 Bibliografía Española, $\mathrm{n}^{\circ} 12,16$ de junio de 1904. Gaceta, 4-VI-1904: «Real decreto disponiendo rija en toda su integridad el reglamento aprobado en 3 de septiembre de 1880 para la ejecución de la Ley de Propiedad Intelectual de 10 de enero de 1879, y que quede derogado el Real decreto de 5 de enero de 1894 que modificó el artículo 30 de dicho reglamento".

${ }_{25}$ Estas ampliaciones se sucedieron en años anteriores (reales órdenes, decretos y órdenes de $1911,1917,1923$ y 1931). Igualmente, se dictaron nuevos decretos que aclaraban o modificaban las reglas de inscripción en el Registro (decretos de 13 de noviembre de 1928 y de 8 de mayo de 1933).

26 A este respecto, resulta de gran interés el estudio de MARTínEZ MARTíN, Jesús A.: «El mercado editorial y los autores. El editor Delgado y los contratos de edición", en Actas del Congreso 'Écrire en Espagne', CNRS-ENS Saint-Cloud, en prensa. Agradezco al autor que me haya permitido la consulta de este artículo.

Hispania, LXII/3, núm. 212 (2002) 993-1020 
Ante estas precarias condiciones, los autores decidieron unirse en la llamada Sociedad de Autores Dramáticos, que se constituyó en 1844, y cuyo objetivo era imprimir sus propias obras y representarlas en el caso de las piezas dramáticas. Formaron parte de la Sociedad de Autores Dramáticos los más famosos escritores del momento: Duque de Rivas, Leopoldo Augusto de Cueto, Patricio de la Escosura, Juan Eugenio Hartzenbusch, etc. No fueron muchas sus realizaciones, pero la trascendencia para el tema que nos ocupa salta a la vista, pues constituyó el primer intento serio de defensa de los propios intereses por parte de los autores. En todo caso, donde más claramente se consolidó el asociacionismo fue en el sector de los autores musicales. Ciertamente, muy pocos literatos en nuestro país podían vivir exclusivamente de la escritura, por lo que escasos afanes existían para defender algo que iba a darles limitados beneficios. Sin embargo, los creadores de obras musicales o de piezas teatrales comenzaron a darse cuenta de que, ante la proliferación de espacios de ocio para una sociedad que cada vez más prefería espectáculos elaborados, se abría un ámbito profesional que podía proporcionarles importantes ventajas económicas. De ahí que de ellos partieran las iniciativas más destacadas en el terreno de la defensa de sus derechos como autores. Durante los últimos veinte años del siglo XIX se sucedieron agrupaciones concebidas para este fin. Primero nació la Asociación de Autores, Compositores y Propietarios Dramáticos, primer estímulo tras la promulgación de la Ley de Propiedad Intelectual de 1879. Más tarde (1881) surgió la Sociedad Lírica Española para gestionar el producto de las representaciones del teatro Apolo de Madrid. En 1892, la Sociedad de Autores, Compositores y Editores, con objeto de administrar las representaciones musicales en lugares públicos. De su tarea se encargaría más tarde la Asociación LíricoDramática (1898). Como derivación de estas dos agrupaciones se creó en 1899 la Sociedad de Autores de España, que contó con Vital Aza como presidente y con Sinesio Delgado como secretario. A ella se unieron los más destacados autores teatrales y musicales del momento: Ruperto Chapí, Carlos Arniches, Tomás Bretón de los Herreros, Federico Chueca, etc. Sus funciones consistían en gestionar el cobro de los derechos de los autores de forma directa tras las representaciones (no de la publicación, que cada autor solía vender a los editores). De ella nacería la actual Sociedad General de Autores de España (S.G.A.E.). Esta sociedad mantuvo una constante preocupación por la Ley de Propiedad Intelectual, en particular por las atribuciones que correspondían a los autores, de ahí que en sus revistas La Propiedad Intelectual, Boletín de la Propiedad Intelectual, Boletín de la Sociedad de Autores Españoles o El derecho de autor, los análisis que se ofrecen son constantes. Para la Sociedad resultó muy apropiado el reconocimiento de lo que se llamaba el "pequeño derecho", es decir, el derecho de ejecución, que era la base de su funcionamiento y fuente principal de ingresos para los asociados. Sobre todas las demás cuestiones reguladas por la ley, la Sociedad de Autores manifestaba un especial rechazo al paso al dominio público de aquellas obras que hubiesen sobrepasado los requisitos temporales ( 80 
años), pudiendo ser publicadas o representadas por cualquier empresario sin que el creador o sus herederos cobrasen por ello. Tal regulación era considerada como un despojo y un atropello a los intereses de los autores ${ }^{27}$.

\section{LA ACTITUD DE LOS EDITORES}

Como se ha señalado repetidas veces, el grupo más marcadamente opuesto a la legislación sobre propiedad intelectual en España fueron los editores. Por parte de los autores y artistas, la protesta no se manifestó públicamente, pues por un lado, no resultaban desfavorecidos ni por la ley ni por el reglamento, y por otro, no se habían organizado en sociedades sólidas que les permitieran una cierta unidad de acción. La ley procuraba importantes ventajas a los editores, pues en gran medida, y ante el grado de desarrollo que estaba empezando a alcanzar la industria editorial en nuestro país, significaba una forma de protección a la industria del libro, ya que, dadas sus diferencias con otros tipos de negocio, apenas había sido regulada su salvaguardia. Pero desde otra perspectiva, esta legislación, tan esperada por el sector editorial, apenas reconocía la propiedad intelectual como una forma común de propiedad. En este sentido, los editores manifestaron sus quejas desde una doble posición, pues si por un lado demandaron precauciones especiales para su industria por cuanto se trataba de algo tan delicado como la elevación cultural del país y la educación de los españoles, por otro, abogaban por el derecho a adquirir plenamente una obra cuando la comprasen a un autor, señalando que la publicación no dejaba de ser un riesgo que ellos corrían y del que se beneficiarían posteriormente los herederos de los autores. Lo único que lograron con sus protestas fue la modificación del ya mencionado decreto de 1894 y la concesión en 1910 de seis meses extraordinarios para inscribir en el Registro las obras que hasta el momento no hubieran sido consignadas. Sin embargo, si de los poderes públicos no se había logrado ninguna cesión, a partir de este asunto, los editores consiguieron organizarse corporativamente, utilizando el pretexto de la lucha contra la ley de 1879 y el decreto de 1880 .

La primera asociación corporativa que apareció en el sector fue el Centro de la Propiedad Intelectual de Barcelona, que nació en 1900 precisamente alrededor de la ley y del decreto, tal y como se especificaba en sus estatutos ${ }^{28}$. El Centro de la Propiedad Intelectual reunía a editores y libreros principalmente de Barcelona, pero también acogía a industriales de otras partes del país. Un año después, en 1901, se fundaba en Madrid la Asociación de la Librería de España, con una finalidad más combativa, según manifestaron repetidas ve-

27 La Propiedad Intelectual, $\mathrm{n}^{\circ}$ 16, octubre de 1915: «Más sobre el dominio público».

28 «Estatutos del Centro de la Propiedad Intelectual», Archivo Nacional de Cataluña, caja 1. 
ces $^{29}$. El Centro de la Propiedad Intelectual y la Asociación de la Librería de España serían el origen, en 1922, a las Cámaras Oficiales del Libro de Madrid y de Barcelona. Su actitud ante la legislación de 1879 y 1880 puede ser considerada un tanto exagerada, pues si bien es cierto que la complicación de los trámites para la inscripción en el Registro convertía esta obligación en una tarea engorrosa, lo cierto es que representaba una forma de protección más sólida que la existente hasta ese momento.

Detrás de las quejas de los editores se hallaba algo más profundo, de lo que ya se ha hablado anteriormente, y era el tratamiento jurídico de la propiedad intelectual. El retorno de los derechos a los herederos una vez que hubiesen pasado veinticinco años desde la adquisición de la obra por parte de un editor era la clave del problema. El presidente de la Asociación de la Librería de Madrid, José Ruiz, manifestó con claridad la situación para los editores:

«Toda propiedad, excepto la intelectual, se adquiere en absoluto. ¿Por qué ha de ser aquélla una excepción y una excepción denigrante para los editores?. ¿Por qué se vende una obra y al cabo de cierto tiempo retrotrae a los herederos del autor o sea, de su primer propietario» 30 .

Estas palabras de José Ruiz se hacían eco de las protestas que en el sector editorial había provocado el conflicto a propósito de la publicación de la Historia de España de Modesto Lafuente. Los derechos habían sido adquiridos en 1876 por Montaner y Simón. En 1908, los herederos de Lafuente, arguyendo que había caducado la propiedad de los anteriores editores, formaron la sociedad Herederos de Lafuente para explotar un negocio más que rentable. El asunto acabó en el Tribunal Supremo, el cual falló a favor de Montaner y Simón, sin embargo, y pese a todo, según la versión de los editores, se había puesto de manifiesto el basamento extraordinariamente frágil en el que se fundaba su industria.

La mayor parte de las situaciones conflictivas que se producían en nuestro país se debían a la carencia de una regulación de los contratos de edición por parte de la ley de 1879 y del decreto de 1880. Los editores españoles, y los autores más implicados en la defensa de sus derechos, plantearon ante los poderes públicos la necesidad de acudir a la legislación extranjera para tomar ejemplo de este tipo de contratos. Mientras tanto, en 1912 el diputado Lino Sánchez Somoza-Torres redactaba y presentaba ante el Congreso un proyecto para regular los contratos de edición que resultaba altamente favorable a los autores. La reacción de los editores no se hizo esperar: Pablo Riera y Sans (presidente del Centro de la Propiedad Intelectual de Barcelona) y Pablo Salvat se dirigieron al diputado Jaime Carner para calibrar las posibilidades de poner

29 Bibliografía Española, ${ }^{\circ} 1,1$ de enero de 1905.

30 Crónica de la Primera Asamblea Nacional de Editores y Libreros, celebrada en Barcelona durante los días 7, 8 y 9 de junio de 1909, Barcelona 1909, p. 60. 
freno en el Congreso al proyecto. Sin embargo, ya se habían pasado los trámites pertinentes en la Cámara baja, por lo que Carner recomendó a los editores catalanes acudir al senador Federico Rahola, dada la próxima vista del proyecto. En el entretiempo, los editores de Barcelona se habían entrevistado con sus compañeros de Madrid, los cuales ante la rápida tramitación del proyecto en el Congreso, se habían resignado a lograr únicamente concesiones parciales ${ }^{31}$. La suerte sonrió a los editores, pues el proyecto quedó detenido en el Senado. Una vez más, detrás de la cuestión de los contratos se hallaba la consideración de la propiedad intelectual, y por tanto, la naturaleza jurídica de los derechos de autor. Hasta fecha tan avanzada como 1934 no apareció una sentencia que clarificase la situación al respecto. La resolución señalaba que los derechos de autor no podrían ser considerados como sueldos, sino como frutos de la propiedad intelectual ${ }^{32}$. Este criterio sirvió para elaborar la orden que establecía la contribución de los editores en materia de impuesto de utilidades ${ }^{33}$. Para los editores, esta regulación, que además no acababa de aclarar la situación plenamente, significó el fracaso de sus campañas públicas para evitar que el impuesto de utilidades recayera sobre la propiedad intelectual, y por extensión, sobre ellos mismos. Las Cámaras del Libro plantearon reformas a esta orden, aunque la Dirección de Rentas Públicas las desestimó totalmente ${ }^{34}$.

Las ediciones clandestinas en América se habían convertido en uno de los principales problemas, tanto para autores como para editores. La existencia de ediciones paralelas y la falsificación afectaban de manera muy considerable al principal mercado de la literatura española, pues aparte de vender a más bajo precio, las obras aparecían mutiladas. Algunos analistas del sector, señalaban que las proporciones alcanzaban diferencias abismales, pues mientras que por una edición legal de la obra de Oscar Wilde El retrato de Dorian Gray se tenían que pagar 2' 50 pesos, por las ediciones clandestinas aparecidas en Argentina se pagaban $50 \operatorname{centavos}^{35}$. Se trataba de ediciones que salían a la luz sobre la original española, usurpando los derechos de autor comprados por el correspondiente editor y publicando ejemplares en pésimo papel y no menos defectuosa tipografía (que a veces hacían difícil la lectura), pero a un precio muy bajo. Detrás de la existencia de este negocio ilegal se encontraba un negocio editorial, el español, cuyas ineficiencias impedían el abastecimiento a los mercados

31 Archivo Nacional de Cataluña, Actas de las sesiones de la Junta General Extraordinaria y del Consejo de Gobierno celebrados en mayo y junio de 1912, caja 1.

32 Bibliografía General Española e Hispanoamericana. Boletín de las Cámaras Oficiales del Libro, $\mathrm{n}^{\circ}$ 12, diciembre de 1934.

33 Orden de 25 de enero de 1935, en Gaceta del 27 de enero de 1935.

34 Archivo Nacional de Cataluña, Actas de las sesiones del Consejo de Gobierno de la Cámara Oficial del Libro de Barcelona, sesión del 26 de marzo de 1936, caja 3.

35 L. Calvo Sotelo, «Orientaciones convenientes a la Cámara del Libro y medios para desarrollar la expansión del libro español», en Bibliografía Española, nº 3, marzo de 1927, p. 25. 
americanos $^{36}$. La mayor parte de los países de América del Sur, salvo Brasil y Haití, no habían firmado el Convenio de Berna y hacia el año 1928 España sólo tenía tratados bilaterales con Colombia, Costa Rica, Ecuador, Guatemala, Méjico, Salvador, Panamá y Paraguay y se hallaba en proceso de negociación con Bolivia, Brasil, Cuba, Chile, Honduras, Nicaragua, Perú, Venezuela y Santo Domingo ${ }^{37}$. Dada esta situación, generalmente los editores y los autores tenían que negociar por su propia cuenta, produciéndose situaciones conflictivas.

Las diversas reuniones corporativas celebradas por los editores analizaron la gravedad de este asunto que tantos problemas económicos les acarreaba, así como las iniciativas estatales para solventarlos. La Conferencia de Editores Españoles y Amigos del Libro, celebrada en Barcelona en junio de 1917 estableció entre sus temas de debate el epígrafe denominado: «Medios conducentes a la mayor garantía en los derechos de propiedad intelectual y su facilidad para establecerlos. Protección en América». En sus conclusiones instaron al gobierno a proteger la edición española en América, señalando que únicamente debería bastar haber inscrito la obra en el Registro de la Propiedad Intelectual español para disfrutar de esa protección ${ }^{38}$. Años más tarde, mediante los decretos de 15 de febrero de 1922 (constitutivo de las Cámaras del Libro) y de 23 de julio de 1925 , se instó a las propias Cámaras para que se encargasen de «cuanto afecte al perfeccionamiento del régimen de la propiedad intelectual, asesorando en los tratados referentes a dicha materia». Sin embargo, no se dotó a las Cámaras de instrumento alguno para proceder a esta labor de asesoramiento hasta que en 1923 el Comité Oficial del Libro se comprometió a crear una comisión técnica asesora del Ministerio de Estado para las negociaciones de los tratados bilaterales referentes a las cuestiones de la propiedad intelectual ${ }^{39}$. Para el año de 1928 se formó definitivamente la comisión que adquirió el nombre de Comité Consultivo de Convenios de Propiedad Intelectual, que estuvo formado por un representante del Ministerio de Instrucción Pública (Alonso Caro, como jefe de la sección de Relaciones Culturales), otro de los editores (Julián Martínez

36 Vid. MARTíneZ RUS, Ana: La proyección editorial en Hispanoamérica en el primer tercio del siglo XX, tesina inédita leída en junio de 1998 (agradezco a la autora que me haya permitido su consulta).

37 LAPIEDRA CABELlO, Xavier: «Indicaciones para fomentar y desarrollar la afición al libro y su producción en España», en Bibliografía Española, n 3, marzo de 1928, p. 27. Con Panamá se firmó un tratado el 31 de mayo de 1913; con Ecuador el 15 de noviembre de 1904; con México, el 6 de abril de 1925; con Perú el 6 de diciembre de 1928; con la República Dominicana el 28 de marzo de 1933. Con algunos países, como Cuba, se habían firmado acuerdos relativos a la inscripción en el Registro de la Propiedad Intelectual de obras producidas por autores cubanos o de la propiedad de cubanos inscritas en Cuba (real orden de 4 de junio de 1928). Vid. SANGroniz, José Antonio: La expansión cultural de España en el extranjero y principalmente en Hispanoamérica, Madrid 1925, RAMA, Carlos: Historia de las relaciones culturales entre España y América Latina: siglo XIX, Madrid 1982.

38 Conferencia de Editores Españoles y Amigos del Libro, celebrada en Barcelona los días 8 y 9 de junio de 1917, Pablo Salvat Editor, Barcelona 1917, p. 79.

39 Gaceta 4-VII-1923: "Real decreto creando en este Ministerio un Comité permanente consultivo de convenios de propiedad intelectual y constituido en la forma en que se indica (2-VII-1923)». 
Reus), otro de los autores (Luis Linares Becerra), un representante de la Sociedad de Autores Españoles (Eduardo Marquina), otro de la Sociedad de Compositores y Músicos (Conrado del Campo) y el jefe del Registro de la Propiedad Intelectual (Emilio Ruiz Cañabate). Pese a la pomposidad que se pretendió dar a esta comisión, lo cierto es que apenas tuvo efectividad en las negociaciones de tratados bilaterales, pues la mayoría de ellos quedaban estancados por años.

En el año 1927, se procedió a la celebración de una conferencia nacional acerca del sector del libro en la que el asunto de la propiedad intelectual ocupó un papel muy importante. Al reunirse en ella personas no sólo del sector editorial, sino también autores, cargos de la administración y personas vinculadas a la prensa, la cuestión fue tratada desde muy distintos puntos de vista, aunque, sin embargo, hubo una única postura oficial acerca de la atribución de la propiedad intelectual. El punto de partida no deja de ser una declaración de buenas intenciones, pues a efectos legales, el hecho de que «la propiedad intelectual pertenece al que la concibe, adquiere o hereda... con independencia de la inscripción en el registro» ${ }^{40}$ no significaba gran cosa, pues no había ningún otro camino para reclamar por una apropiación ilegal de los derechos de autor. La vieja demanda de los editores y, en menor medida, de los autores, es decir, la no-obligatoriedad de inscribir en el registro, continuaba siendo el punto de inflexión y, en última instancia, de garantía. Ante la ley, la celebración de contratos entre las dos partes no era suficiente precaución. La segunda parte de la enunciación mostraba el interés general por promover una nueva legislación al respecto, iniciativa que no llegó a ninguna parte, como tantas otras en el sector del libro en España. Tres años después, las Cámaras del Libro, ante la inexistencia de movimiento de los poderes públicos para proceder a la tan deseada reforma de la ley, decidieron iniciar una campaña pública para incitar a la reforma. Entre sus propuestas se hallaba el debate acerca de la inscripción en el registro de las publicaciones para cuyo complemento sugerían otorgar la gestión al cuerpo de archiveros, a modo de fe pública para el reconocimiento de la propiedad intelectual ${ }^{41}$.

Pese a las críticas a la obligatoriedad de la inscripción, frecuentemente era esta exigencia la que salvaba las desavenencias que surgían entre los mismos editores. Tal resultó ser el caso del conflicto que enfrentó entre 1931 y 1932 a la Editorial Bauzá con la revista Novelas y Cuentos, la cual había publicado el relato de H.G. Wells El hombre invisible. Bauzá no había inscrito en el Registro la traducción que realizó su empresa sobre el derecho exclusivo que había comprado al autor por el relato. La revista Novelas y Cuentos alegó la inexistencia de inscripción en el Registro como excusa. Las Cámaras del Libro de Madrid y de

40 Libro de actas y acuerdos de la Conferencia Nacional del Libro, celebrada en Madrid en el Palacio del Senado, durante los días 21 al 26 de marzo de 1927, Gráficas Reunidas, S.A., Madrid 1927, p. 335.

41 Archivo Nacional de Cataluña, Libro de Actas de la Cámara Oficial del Libro de Barcelona, sesión del Consejo de Gobierno de 6 octubre de 1930.

Hispania, LXII/3, núm. 212 (2002) 993-1020 
Barcelona, que actuaron como mediadoras, decidieron resolver tras haber investigado si el autor había vendido dos veces el mismo derecho de traducción y haber verificado si, efectivamente, constaba o no en el Registro la ficha de la mencionada traducción. Al margen de los detalles particulares, este caso pone en evidencia varias cuestiones. La primera es que ante potenciales conflictos, no había más posibilidad legal de corroborar la publicación que comprobando el Registro, y no basándose en la mera aparición del libro, como pedían muchos editores y autores. El laudo de las Cámaras así lo manifestaba:

«En consecuencia, por lo que se refiere concretamente al derecho exclusivo de don Bartolomé Bauzá, éste ha perdido sus derechos si la obra no ha sido registrada y cualquiera puede publicarla previa autorización de don H.G. Wells que protegido por el Convenio de Berna no pierde nunca su propiedad. Por ello, si la obra no está registrada, el autor puede nuevamente ceder su derecho».42

La segunda cuestión que muestra este caso es que las asociaciones de editores, es decir, las Cámaras, eran muy conscientes de que con demasiada frecuencia sus asociados no inscribían las obras, de ahí que para evitar conflictos mayores y enfrentamientos en los tribunales, se ofrecieran para actuar como mediadoras, sobre todo desde que a la Cámara de Madrid le fue autorizado inspeccionar en el Registro el estado de las distintas editoriales sin necesidad de permiso de los propietarios ${ }^{43}$.

No sería hasta 1934 cuando se publicó una orden por la cual se iniciaba el proceso de reforma de la ley de 1879 y del reglamento de $1880^{44}$. La orden apuntaba un concepto interesante que gustó especialmente a los editores y autores:

«la ley de 1879 consagra ciertos principios, hoy en absoluto desechados por todas las legislaciones, como el de que la propiedad nace en el acto de la inscripción de las obras en el Registro de la Propiedad Intelectual o impone para la inscripción trámites formularios que entorpecen el registro».

Una vez más, se observa cómo el punto de inflexión vuelve a estar situado en el momento y la persona en la que se asienta el derecho de propiedad. Una razón más compelía al gobierno de Lerroux a dictar la orden y era la colusión de determinados aspectos de la ley de 1879 y el reglamento de 1880 con el Convenio de Berna que había sido revisado en 1928 en una reunión interna-

42 Biblioteca de Cataluña, Sala Bergnes de las Casas, «Expediente Bauzá-Novelas y Cuentos» (caja 94).

43 Gaceta de 3 de agosto de 1930: «Real orden autorizando a la Cámara Oficial del Libro de Madrid para verificar en el Registro General de la Propiedad Intelectual la inscripción de las obras editadas por los editores pertenecientes a la misma, sin especial autorización de los autores en cada caso, y fijando las reglas que se expresan sobre edición de obras, 26 de julio de 1930».

44 Orden del 24 de febrero de 1934, en Gaceta del 25 de febrero de 1934. 
cional celebrada en Roma. Otra cuestión se añadía a la anterior; se trataba de la posible adhesión de varios países del sur de América al Convenio de Berna, por lo que a España le convenía tener su legislación adaptada a tal circunstancia, con objeto de poder atajar la piratería editorial de la que eran objeto los autores y empresarios españoles. La orden establecía la formación de una comisión que tendría entre sus objetivos el de fijar las bases sobre las que se procedería a la reforma de la legislación. La comisión estuvo formada por las siguientes personas: Miguel Artigas (director de la Biblioteca Nacional), Luis Gil Fillol (Asociación de la Prensa), José Ruiz Castillo (presidente de la Cámara del Libro de Madrid), Santiago Salvat (presidente de la Cámara del Libro de Barcelona), Gustavo Gili (Instituto de Economía Americana de Barcelona), José Pereiro (jefe del Registro de la Propiedad Intelectual), Wenceslao Fernández Flórez (autor), José Francés (Academia de Bellas Artes de San Fernando), Julio Moisés (presidente de la Asociación de Pintores y Escultores), Serafín Álvarez Quintero (autor dramático), Conrado del Campo (compositor y académico), Ricardo Urgoiti (director de Unión Radio), Joaquín Guichot (secretario de la Sociedad General de Autores), José Sánchez Gerona (grabador) y Joaquín Vernacci (fotógrafo). Una vez establecidas las bases, se presentó un proyecto de ley que fue sometido a examen público ${ }^{45}$.

Entre las cuestiones más tratadas en el proyecto de ley se hallaba la definición de propiedad intelectual, que trataba de abarcar todas las manifestaciones artísticas y las nuevas formas de expresión nacidas del desarrollo de la fotografía y su utilización en nuevos ámbitos (por ejemplo, en libros y periódicos) y del cine. El artículo $2^{\circ}$ del proyecto otorgaba precisión al concepto que hasta el momento se había expresado con bastante vaguedad:

«Esta facultad, llamada 'Derecho de autor', abarca las modalidades siguientes: edición, representación, ejecución, traducción, adaptación, reproducción, difusión, comunicación y utilización en general de la obra».

Los artículos siguientes desarrollaban con detenimiento cada una de estas modalidades expresivas, recogiendo los derechos consagrados en la Conferencia de Berlín de 1908 y en la de Roma de 1928, que revisaban el Convenio de Berna. Sin embargo, y a pesar de los intentos de los editores presentes en la comisión, el proyecto continuaba manteniendo los ochenta años como periodo de pertenencia de los derechos de autor a los herederos (artículo 20). El texto resguardaba la figura del autor, y no sólo al volver a reconocer los ochenta años, sino también al atribuirle el derecho absoluto sobre su obra. En efecto, el artículo 19 habla del «derecho moral del autor» (concepto jurídico de amplia

45 Archivo General de la Administración-Archivo del Ministerio de Educación y Cultura, caja 6077. El proyecto se completaría con el informe elaborado por la Dirección General de Bellas Artes (Sección de Archivos, Bibliotecas, Museos Arqueológicos y Propiedad Intelectual) a petición de la Asociación General de Escritores y Periodistas de España (caja 6076).

Hispania, LXII/3, núm. 212 (2002) 993-1020 
trayectoria internacional), y aunque un poco prolongado, resulta interesante su contenido, de ahí que se reseñe aquí totalmente:

«El derecho moral del autor es inalienable. Por tanto, independientemente de los derechos patrimoniales, y aun después de la cesión de éstos, el autor conserva siempre la facultad de reivindicar la paternidad de la obra, así como la de oponerse a cualquier deformación, mutilación o modificación de ella que para su honor o prestigio fuera perjudicial. Las obras de importancia notoria para el arte, la educación o la cultura, no podrán ser modificadas o alteradas después de la muerte del autor en forma que disminuya su valor o estimación pública. Las Corporaciones que por precepto de la ley o de sus estatutos estén encargadas de la defensa o custodia de los intereses literarios, culturales o artísticos, tendrán derecho a impedir que no se perjudique o deprecie la obra, y a tal efecto podrán solicitar del Estado que adopte las medidas necesarias».

Se retoma, como ya hemos visto en otros textos legislativos, la vieja idea de Condorcet de la obra cultural como producto social, idea que tradicionalmente había sustentado la noción del paso al dominio público de las obras literarias y artísticas. Igualmente, se sitúa al derecho moral como tutela superior del derecho patrimonial. Por otra parte, la inscripción en el Registro de la Propiedad Intelectual seguía siendo una condición básica y obligatoria, estableciéndose un plazo de tres meses desde la publicación de libros o el estreno de obras dramáticas y musicales para proceder al cumplimiento de los trámites ${ }^{46}$. Pese a estas condiciones, los editores consiguieron que en el artículo 75 se garantizase la propiedad aunque aún no estuviese la obra inscrita en el Registro. Del mismo modo, el proyecto de ley recogía otra de las grandes lagunas legislativas del sector editorial como era la regulación de los contratos de edición, bajo el epígrafe de «Derivaciones de la propiedad intelectual» ${ }^{47}$.

Los editores, principales afectados por el proyecto, expresaron su opinión en el Boletín de las Cámaras Oficiales del Libro de Bibliografía General Española e Hispanomericana de diciembre de 1934. Allí mostraron su oposición al prolongado periodo de permanencia de los derechos de autor, apuntando que resultaba una gran sinrazón el que el autor pudiese dejar a sus herederos lo que él mismo ya había vendido al editor, señalando que «el editor habrá de tenerlo muy en cuenta al firmar los contratos de adquisición de obras y mermará los precios considerablemente porque la amenaza de pagar un censo a los herederos del autor se lo hará inevitable». Este nuevo debate, recién iniciado, en el que se mezclaban intereses económicos con cuestiones jurídicas y en el que se definía

46 Los editores fueron autorizados, por medio de las Cámaras oficiales del Libro de Madrid y de Barcelona, a registrar directamente y a nombre de los autores, las obras que editasen (Archivo General de la Administración-Archivo del Ministerio de Educación y Cultura, caja 6077).

47 El proyecto de ley en Diario de Sesiones de Cortes, 28-junio-1934, apéndice al no 108 . Fue reproducido en el Bibliografía Española. Boletín de las Cámaras Oficiales del Libro en los siguientes números: 6 (junio de 1934), 7-8 (julio-agosto de 1934), 9 (septiembre de 1934) y 10 (octubre de 1934). 
el nuevo estatus del autor, quedó totalmente oscurecido por el estallido de la Guerra Civil, olvidándose el tan anhelado proyecto de reforma de la ley de 1879 ante las urgencias que planteaban los acontecimientos políticos.

\section{CONCLUSIONES}

A lo largo de estas páginas se ha intentado ofrecer una visión panorámica de la evolución de la legislación sobre propiedad intelectual en nuestro país y la recepción que de la misma hicieron los grupos sociales afectados por ella. Como se ha podido ver, el proceso se hizo más complejo durante el primer tercio del siglo XX, sobre todo a medida que el sector editorial se fue desarrollando y que las empresas se hicieron más sólidas. El desarrollo de la industria editorial favoreció, además, la profesionalización del escritor. De este modo, ambos grupos, editores y autores, más conscientes de su situación, plantearon más claramente sus necesidades ante las autoridades. Junto a ellos se encontraban los autores y empresarios teatrales y musicales, muy interesados en las cuestiones de la regulación de la propiedad intelectual por cuanto su negocio era el más rentable. Podemos decir, por tanto, que la gran transformación del sector se produjo en los primeros treinta años del siglo, aunque la legislación no fue capaz de hacerse eco de sus demandas.

Uno de los problemas más importantes, que sólo se recogió en el proyecto de 1934 , es el que se refiere a los contratos de edición. La inexistencia de regulaciones al respecto obligó a que autores y editores obrasen por propio acuerdo. El porcentaje correspondiente a derechos de autor, a la luz de los documentos que nos han quedado, oscilaba entre el 10 y el $15 \%$. Como ejemplo se podría citar el contrato firmado por Jardiel Poncela con Ruiz-Castillo (Biblioteca Nueva) por Amor se escribe sin bache, por el que el autor cobraría tres reales por cada ejemplar vendido, lo que éste consideraba una cantidad escasa ${ }^{48}$. Jardiel pudo cobrar más dinero posteriormente, pero sólo porque, en ediciones sucesivas, el editor subió el precio del libro, y no porque aumentara su porcentaje en derechos de autor. Sin embargo, escritores de la categoría de Valle Inclán se quejaban de que les ofrecían la irrisoria cantidad del $5 \%$ por algunas de sus obras ${ }^{49}$. Ante tales opciones, muchos optaban por autoeditarse. Al no haber contemplado la cuestión de los contratos, la ley de 1879 perjudicaba a los autores, quienes, salvo los de más éxito, no se encontraban en situación de poner condiciones a sus editores.

Al lado de las cuestiones más puramente materiales, relacionadas con la explotación económica del derecho de autor, la evolución de la legislación sobre

\footnotetext{
48 Vid. Sanchez García, Raquel, «Enrique Jardiel Poncela y su editor José Ruiz Castillo», en Pliegos de Bibliofilia, 15 (2001) pp. 3-18.

49 Valle-InClan, R., Entrevistas, Alianza Editorial, Madrid 2000, p. 225.

Hispania, LXII/3, núm. 212 (2002) 993-1020
} 
propiedad intelectual revela la profunda transformación que sufrió la figura del autor desde el siglo XIX hasta que empezó a entrar en el circuito mercantil de a compra y la venta. Prestas a ser olvidadas ya las viejas ideas románticas al respecto, el autor se insertará en el proceso productivo como un eslabón más, vendiendo un producto de su creación. José María Salaverría, sagaz observador, lo apuntó con estas palabras:

«El escritor, desposeído ya de melenas, barbas, chalinas y demás agregados peculiares, va entrando en el régimen social común, de las disciplinas corrientes y universales. Es un hombre a sueldo, por jornal o a destajo, que trabaja todos los días en su taller y sirve los encargos lo mejor que puede, ahora un cuento, en seguida una conferencia, un artículo, un drama. Por tanto, tendrá que someterse a las mismas leyes y obligaciones que los otros hombres; no se le consentirá la postura de niño mimado o de hermoso Lucifer a lo Lord Byron» 50.

so «La moral del literato», en $A B C, 17-3-1928$. 